\title{
Huge Infected Cephalohematoma Associated with Meningitis: A Case Report
}

Jui-Shan $\mathrm{Ma}^{1,2^{*}}$

${ }^{1}$ Department of Pediatrics, Feng-Yuan Hospital, Ministry of Health and Welfare, Executive Yuan, Taichung, Taiwan ${ }^{2}$ College of General Education, HungKuang University, Taichung, Taiwan

\section{Abstract}

Infected cephalohematoma associated with meningitis is rare in neonatal period. Herein we report a neonate with huge infected cephalohematoma associated with meningitis, which was caused by Escherichia coli. With intravenous antibiotic therapy and surgical drainage of the infected cephalohematoma, he became afebrile soon. Intravenous ceftriaxone therapy was continued for 21 days and no sequela was reported. It is suggested that meningitis should be considered in neonates with infected cephalohematoma

\section{Publication History:}

Received: November 30, 2017

Accepted: December 27, 2017

Published: December 29, 2017

\section{Keywords:}

Neonate, Huge infected cephalohematoma, Meningitis

\section{Introduction}

Cephalohematoma in the neonate results from accumulation of blood between the bone and periosteum. The incidence is reported as $0.4 \%$ to $2.5 \%$ in previous literature [1]. Bacterial infection is rarely complicated with a cephalohematoma and it is usually associated with sepsis, meningitis, or osteomyelitis of the underlying skull bone. Escherichia coli is the most common organism to be encountered, whereas Staphylococcus aureus, coagulase-negative staphylococci, Streptococcus pneumoniae, Bacillus spp., Pseudomonas spp., Proteus spp., Salmonella spp., Gardnerella vaginalis, group B streptococcus, and anaerobes are less common pathogens [2-6]. A recent study further highlights the polymicrobial nature and potential importance of anaerobic bacteria in infected cephalohematoma (IC) in neonates [7]. Gram negative rods represent the predominant bacteria of IC with concurrent meningitis in several literature reviews $[1,2,8,12,17]$. With antibiotic therapy and surgical drainage, we describe a neonate with huge IC with concomitant meningitis, recovered without any sequela. blood count revealed white blood cell (WBC) count of $13,400 / \mathrm{mm}^{3}$ with left shift. The C-reactive protein (CRP) level was $9.86 \mathrm{mg} / \mathrm{dL}$. Intravenous ampicillin $(150 \mathrm{mg} / \mathrm{kg} /$ day $)$ and gentamicin $(5 \mathrm{mg} /$ $\mathrm{kg} /$ day) were used as empiric antibiotic therapy after initial septic workup. As fever and irritability persisted on the second admission day, brain sonography was done with no intracranial lesion noted. The cerebrospinal fluid (CSF) study revealed WBC count of 340/ $\mathrm{mm} 3$ (with $8 \%$ neutrophils, $82 \%$ lymphocytes, and $8 \%$ monocytes), red blood cell (RBC) count of $50 / \mathrm{mm}^{3}$, glucose level of $32 \mathrm{mg} /$ $\mathrm{dL}$, and total protein level of $137 \mathrm{mg} / \mathrm{dL}$. With the consideration of concomitant meningitis, intravenous ceftriaxone $(100 \mathrm{mg} / \mathrm{kg} /$ day $)$ therapy was started. The bacterial culture of blood and CSF yielded no microorganism. Low grade fever persisted and the cephalohematoma enlarged progressively. He received incision and drainage and became afebrile on the next day. The evacuated pus culture grew $E$. coli, which is susceptible to amipicillin, gentamicin, and ceftriaxone. Totally, he received intravenous ceftriaxone therapy for 21 days and no sequela is reported.

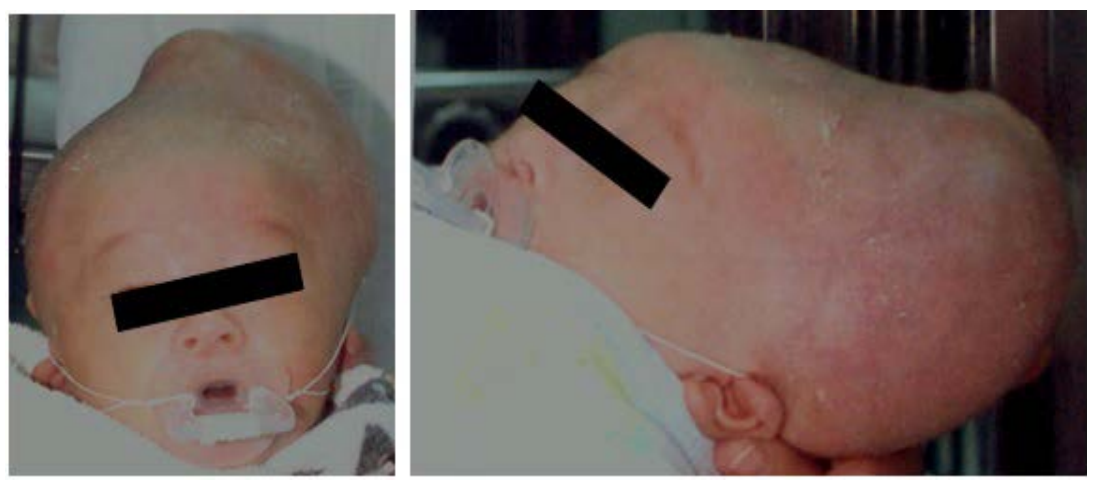

Figure 1: A huge infected cephalohematoma in a 13-day-old neonate.

\section{Case report}

A 13-day-old, full-term, male neonate who was born via spontaneous vaginal delivery without vacuum extraction suffered from progressive enlargement of his occipital cephalohematoma for one week. He became febrile and irritable since 2 days prior to admission. On examination, a huge cephalohematoma $(18 \mathrm{~cm}$ in the greatest dimension) with fluctuation and local heat was noted (figure 1). The overlying skin was erythematous but intact. His anterior fontanel was neither tense nor bulged. The other physical and neurological examinations were unremarkable. A complete
"Corresponding Author: Dr. Jui-Shan Ma, Department of Pediatrics, FengYuan Hospital, Ministry of Health and Welfare, Executive Yuan, 100 An-Kan Rd. Fengyuan Dist., Taichung City 42055, Taiwan; E-mail: jma052968@gmail.com

Citation: Ma JS (2017) Huge Infected Cephalohematoma Associated with Meningitis: A Case Report. Int J Pediatr Neonat Care 2: 133. doi: https://doi. org/10.15344/2455-2364/2017/133

Copyright: (c) $2017 \mathrm{Ma}$. This is an open-access article distributed under the terms of the Creative Commons Attribution License, which permits unrestricted use, distribution, and reproduction in any medium, provided the original author and source are credited. 


\section{Discussion}

An infected cephalohematoma is rare but potentially lifethreatening condition in neonates. Meningitis is rarely reported to be associated with IC in previous literature. In Taiwan, Chang et al. reported 3 of 28 infants with IC to be associated with meningitis in a period of 25 years [3]. A recent literature review reported 11 of 43 infants had IC with concurrent meningitis. The causative bacteria are predominately gram negative rods, especially $E$. coli [8]. The overall mortality rate remains high and which is related to the delayed diagnosis of meningitis and lack of surgical drainage [3,5,8-12].

The association of meningitis might result from bacteremic seeding or direct extension through the infected skull bone [13,14]. Focal extension accounts for the association of underlying skull bone osteomyelitis with negative blood culture and concurrent meningitis. Radiographic studies and bone scan may provide useful information in the differentiation of underlying skull bone osteomyelitis $[8,13,14]$

In the current case, delayed CSF study with previous exposure to antibiotics leads to the sterile result. Early detection of the association of meningitis is crucial, because prolonged therapy of antimicrobial agents with good tissue penetration is necessary for successful treatment. If such association is ignored, serious complication, including mortality, may ensue [15-17]. It is suggested CSF study is indicated for neonates with IC [5].

The current case received surgical drainage and antibiotic therapy for a total of 3 weeks. The adequate durations of antibiotic therapy have not yet been established. However, it is suggested that neonates with IC and concurrent bacteremia, meningitis, and osteomyelitis, to receive antibiotic therapy for at least 2-3 weeks, 3-4 weeks, and 4-6 weeks, respectively $[6,15]$. Surgical drainage plays an important role in the management of IC and failure of treatment has been reported with antimicrobial therapy alone $[4,8-10,16-18]$. Repeated needle aspiration is also found to be a safe and effective alternative procedure for IC in neonates [6].

\section{Conclusion}

In conclusion, meningitis should be considered in neonate with IC. It necessitates appropriate selection of antibiotics with ability to penetrate blood-brain barrier and a prolonged period of therapy. Early detection of such association is crucial and related to their prognosis. Therefore, we suggest that CSF study is warranted for initial workup in such patients, if no contraindication exists. Further studies are necessary to confirm our findings and suggestions.

\section{Competing Interests}

The authors declare that they have no competing interests.

\section{Reference}

1. Lee YH, Berg RB (1971) Cephalohematoma infected with bacteroides. Am J Dis Child 121: 77-78.

2. Huang CB, Wu KT, Hung FC, Huang SC (1996) Infected cephalohematoma in neonate. Clin Neonatol 3: 23-26.

3. Chang HY, Chiu NC, Huang FY, Kao HA, Hsu CH, Hung HY (2005) Infected cephalohematoma of newborns: experience in a medical center in Taiwan. Pediatr Int 47: 274-277.
4. Dahl KM, Barry J, Debiasi RL (2002) Escherichia hermannii infection of a cephalohematoma: case report, review of the literature, and description of a novel invasive pathogen. Clin Infect Dis 35: e96-e98.

5. Cohen SM, Miller BW, Orris HW (1947) Meningitis complicating cephalohematoma. J Pediatr 30: 327-329.

6. Wang LY, Chen CH, Chen PY, Huang FL, Chi CS (1999) Infected cephalohematoma caused by salmonella infection. Clin Neonatol 6: 22-24.

7. Brook I (2005) Infected neonatal cephalohematomas caused by anaerobic bacteria. J Perinat Med 33:255-258.

8. Zimmermann P, Duppenthaler A (2016) Infected cephalhaematoma in a five-week-old infant - case report and review of the literature. BMC Infect Dis 16: 636 .

9. Gorden HS, Aronow J (1955) Escherichia coli meningitis in a five-day-old infant complicated with infected cephalohematoma. JAMA 159:1288.

10. Burry VF, Hellerstein S (1966) Septicemia and subperiosteal cephalohematoma. J Pediatr 69: 1133-1135.

11. Levy HL, O'Connor JF, Ingall D (1967) Bacteremia, infected cephalohematoma, and osteomyelitis of the skull in a newborn. Am J Dis Child 114: 649-651.

12. Chiu FY, Lee CY (1972) Spontaneous infection of cephalhematoma: a report of four cases. Acta Paed Sin 13: 12-17.

13. Fan HC, Hua YM, Juan CJ, FangYM, Cheng SN, Wang CC (2002) Infected cephalohematoma associated with sepsis and scalp cellulitis: a case report. J Microbiol Immunol Infect 35: 125-128.

14. Mohon RT, Mehalic TF, Grimes CK, Philip AGS (1986) Infected cephalohematoma and neonatal osteomyelitis of the skull. Pediatr Infect Dis J 5: 253-256.

15. Nakwan N, Nakwan N, Wannaro J, Dissaneevate P, Kritsaneepaiboon S, et al. (2011) Septicemia, meningitis, and skull osteomyelitis complicating infected cephalhematoma caused by ESBL-producing Escherichia coli. Southeast Asian J Trop Med Public Health 42: 148-151.

16. Blom NA. Vreede WB (1993) Infected cephalhematomas associated with osteomyelitis, sepsis and meningitis. Pediatr Infect Dis J 12: 1015-1017.

17. LeBlanc CM, Allern UD, Ventureyra E (1995) Cephalohemtomas revisited: when should a diagnostic tap be performed? Clin Pediatr 34: 86-89.

18. Huang CS, Cheng KJ, Huang CB (2002) Infected cephalohematoma complicated with meningitis: report of one case. Acta Pediatr Tw 43: 217219. 